\title{
Visão Empreendedora dos Alunos do Curso de Administração de uma Universidade Pública
}

\author{
Entrepreneurial Vision of the Students of the Administration Course of a Public \\ University
}
Visión Emprendedora de los Estudiantes del Curso de Administración de una Universidad Pública

\author{
Andreia Kaviak ${ }^{1}$ \\ Discente de administração: UNICENTRO/PR \\ kaviakandreia@gmail.com \\ http://bit.ly/QwZDcd \\ https://orcid.org/0000-0002-6174-7939 \\ Cláudio Luiz Chiusoli ${ }^{1}$ \\ Docente de administração: UNICENTRO/PR \\ prof.claudio.unicentro@gmail.com \\ http://bit.ly/QwZDcd \\ http://orcid.org/0000-0002-7844-3632
}

Universidade Estadual do Centro-Oeste, UNICENTRO, Brasil ${ }^{1}$

Artigo recebido em 02.04.2019. Última versão recebida em 18.05.2019. Aprovado em 21.06.2019. 


\title{
Resumo
}

Esse trabalho tem como objetivo identificar a opinião e atitude do estudante de Pitanga, do curso de Administração da Unicentro, a respeito da sua visão empreendedora. Foi possível identificar os interesses empreendedores dos mesmos e a motivação cedida de seus familiares em possuir seu próprio negócio, tendo sido realizada também um comparativo com outra pesquisa, realizada no campus Santa Cruz/Unicentro. A pesquisa foi realizada com 100 acadêmicos do campus de Pitanga, com cunho quantitativo, sendo também realizado nos quatro anos do curso de administração, em uma tentativa de Censo. O referencial abordou aspectos relevantes às características, às habilidades dos empreendedores e sua motivação empreendedora, bem como uma definição sobre o assunto. Com que se refere aos achados da pesquisa, verificou-se que a busca pelo empreendedorismo ocorre principalmente devido à influência por estar cursando administração. Outra implicação importante para o fato de desejarem se tornar um empreendedor é ter um ganho financeiro extra, de forma que possa haver uma independência mediante renda própria.

Palavras-chave: Empreendedorismo. Competências Administrativas. Motivação Empreendedora.

\section{Entrepreneurial Vision of the Students of the Administration Course of a Public University}

\begin{abstract}
This paper aims to identify the opinion and attitude of the student of Pitanga of the course of Administration of Unicentro with respect to his entrepreneurial vision. It was possible to identify their entrepreneurial interests and the motivation given by their relatives to own their own business, also carried out a comparison in another research carried out at the Santa Cruz / Unicentro campus. The research was carried out with 100 academics of the campus of Pitanga with quantitative mark, is also realized in the four years of the course of administration in an attempt of Census. The referential focused on aspects relevant to the characteristics, entrepreneurs' abilities and their entrepreneurial motivation, as well as a definition of the subject. With regard to the findings of the research, it was verified that the search for entrepreneurship occurs, mainly, due to the influence of being in administration. Another important implication of their desire to become an entrepreneur is an extra financial gain so that there can be independence through own income.
\end{abstract}

Keywords: Entrepreneurship. Administrative Skills. Entrepreneurial Motivation.

\section{Visión Emprendedora de los Estudiantes del Curso de Administración de una Universidad Pública}

\section{Resumén}

Este trabajo tiene como objetivo identificar la opinión y actitud del estudiante de Pitanga del curso de Administración de Unicentro respecto a su visión emprendedora. Fue posible identificar los intereses emprendedores de los mismos y la motivación cedida de sus familiares en poseer su propio negocio, realizado también un comparativo en otra investigación realizada en el campus Santa Cruz / Unicentro. La encuesta fue realizada con 100 académicos del campus de Pitanga con cuño cuantitativo, siendo también en los cuatro años del curso de administración en un intento de Censo. El referencial abordó las 
características, las habilidades de los emprendedores y su motivación emprendedora, entre también una definición sobre el asunto. Con que se refiere a los hallazgos de la investigación se verificó que la búsqueda por emprender ocurre debido a la influencia por estar estudiando administración. Otra implicación por el hecho de desear convertirse en un emprendedor es motivado para una ganancia extra financiera, que pueda haber una independencia mediante ingresos propios.

Palabras clave: Emprendimiento. Competencias Administrativas. Motivación Emprendedora. 


\section{INTRODUÇÃO}

O empreendedorismo é muito importante para o desenvolvimento econômico, que organiza recursos para gerenciamento de alguma uma atividade, e o empreendedor é mais conhecido para quem cria novos negócios, como inovação dentro de negócios já existentes, como citava Shumpeter, que lançou o campo empreendedorismo associado à inovação, cuja essência está na percepção de aproveitar oportunidades nos âmbitos dos negócios (Filion, 1999; Bride, 2009).

O movimento empreendedorismo começou a tomar forma na década de 90 , em programas criados em todo país junto a incubadoras de empresas e universidades, desta forma o tema empreendedorismo começou a despertar na sociedade brasileira, onde a expressão empreendedor significa aquele que assume riscos e começa algo novo (Silva \& Chiusoli, 2016).

A análise histórica do empreendedorismo tem suas fases, que inicia com o que pode ser creditado a Marco Polo que, como empreendedor, assinou um contrato com um homem que possuía dinheiro (capitalista) para vender as mercadorias deste. E em seguida surgiram os primeiros indícios na relação entre empreender e assumir riscos, o empreendedor nesta época estabelecia um acordo contratual com o governo para realizar algum serviço ou fornecimento, assumia riscos com lucros e prejuízos.

Atualmente, há diferença entre o capitalista e o empreendedor. Devido ao início da industrialização, os empreendedores foram frequentemente confundidos com os gerentes e administradores, e como a característica de um empreendedor é ser visionários, habilitando-se por programar sonhos e tomar decisões, explorando ao máximo as oportunidades (Dornelas, 2009).

Nesse sentido, um estudo exploratório realizado junto aos alunos de Guarapuava, do curso de administração, campus Santa Cruz/Unicentro, apontou que $40 \%$ dos participantes consideramse um empreendedor; e 54\% já possui algum empreendedor na família (Silva \& Chiusoli, 2016).

Desta forma, a justificativa do estudo é tentar apontar um comparativo de como alunos do campus, avançados no curso de administração de Pitanga, se comportam dentro desse assunto, que é ser empreendedor. A questão problema é: qual a avaliação da importância de ser um dia empreendedor como motivação de novos oportunidades de renda extra por parte dos alunos do curso de administração do Campus Avançado de Pitanga?

O objetivo do estudo é identificar a opinião e atitude do estudante de Pitanga, do curso de Administração da Unicentro, a respeito da sua visão empreendedora. Como objetivos norteadores, têm-se como proposta: i) verificar se existe alguma influência pelo fato de ser aluno de administração; ii) levantar a intenção de um dia torna-se empreendedor; iii) identificar se na família há empreendedores; iv) levantar os motivos pelas quais desejaria ser um empreendedor; e v) comparar os resultados obtidos com pesquisas realizadas no Campus de Santa Cruz.

\section{REFERENCIAL TEÓRICO}


Para alinhamento teórico a respeito do tema, realiza-se um levantamento bibliográfico que descreve a respeito do comportamento do empreendedor; as características empreendedoras; habilidades do empreendedor e motivação empreendedora.

\subsection{Comportamento do empreendedor}

O empreendedorismo está presente no cotidiano das pessoas, estando no cotidiano de cada um, é um tema que vem se alavancando a cada dia, com novas ideias inovadoras e seus diferenciais momentâneos, sendo assim, o empreendedor é aquela pessoa que vai além do objetivo inicial.

O termo empreendedorismo foi usado pelo economista Joseph Schumpeter, em 1950, como sendo, de forma resumida, uma pessoa com criatividade e capaz de fazer sucesso com inovações (Schumpeter, 1997).

Seguindo a mesma linha de pensamento, Dornelas (2001) identifica como sendo o empreendedor aquele que assume os riscos, físicos e emocionais, de forma ativa; e o capitalista assume os riscos de forma passiva. Para Filion (1999), um bom exemplo de empreendedor são as pessoas que têm ambição de realizar alguma coisa na vida.

Empreendedorismo é o processo de criar algo novo com valor, dedicando o tempo e o esforço necessários, assumindo os riscos financeiros, psíquicos e sociais correspondentes e recebendo as consequentes recompensas da satisfação e independência econômica e pessoal (SEBRAE, 2007).

Para Hisrch e Peters (2004), o empreendedorismo é o processo dinâmico de criar mais bens e para Freire (2005), o empreendedor é aquela pessoa que detecta uma oportunidade e cria uma organização para concretizá-la; e, de acordo com sua experiência de vida, não é necessário ser rico, jovem ou universitário para empreender, o que é preciso é ter coragem e convicção do que se quer empreender.

O empreendedor é o responsável pela criação de novos produtos e mercados que superariam os anteriores, sendo assim, apresentam vantagens, como maior eficiência e menor custo (Degen, 1989). Kiggundu (2002) acredita, inclusive, que a educação e o treinamento empreendedor podem ser visualizados pela perspectiva de desenvolvimento de competências empreendedoras, sendo importante desenvolver programas educacionais específicos para empreendedores.

Dornelas (2007) considera como mito o fato de empreendedores serem natos e nascerem para o sucesso, pois é com o passar dos anos que eles acumulam experiências, habilidades relevantes, contatos e capacidade de ter visão e perseguir oportunidades. Há muitas definições sobre o termo empreendedorismo, sabendo que elas estão em constantes evoluções, à medida das mudanças da sociedade e as constantes mudanças econômicas tornam-se mais complexas.

\subsection{Características empreendedoras}

Para Filion e Dolabela (2000), as características empreendedoras podem ser adquiridas e desenvolvidas, uma vez que a preocupação de identificar o perfil do empreendedor de sucesso auxilia no processo de aprender a agir, adotando comportamentos e atitudes adequadas para se tornar um. 
Assim, pode-se definir o perfil do empreendedor como a descrição de uma pessoa em traços mais ou menos rápidos. Silva (2014) define dois tipos de perfil: o perfil ideal e o perfil real. O perfil ideal é uma abstração formada a partir das exigências de novas interpretações das abordagens administrativas já existentes e também da necessidade de compreensão dos novos campos do conhecimento humano. Já o perfil real engloba o perfil ideal, juntamente comas características pessoais e a influência do meio.

Existem diversas características que são fundamentais em um empreendedor, dentre elas destaca-se: autoconfiança, foco em oportunidade, conhecer muitas pessoas, saber calcular e minimizar riscos, poder de persuasão e, principalmente, paixão pelo que faz (Custódio, 2011).

No ambiente empresarial existe uma grande variedade de atributos envolvendo o empreendedor. Tudo depende do nível de empreendedorismo do proprietário, da natureza e amplitude do trabalho do empreendedor, do tipo de atividade do empreendimento, entre outros (Cielo, 2001).

O empreendedorismo está associado à criação de novas empresas, de algo novo e de valor. O empreendedor deverá estar totalmente compromissado com o desenvolvimento e crescimento do novo negócio, a existência de riscos calculados é inevitável, sendo assim, os mesmos deverão assumir as decisões realizadas com ousadia e coragem (Pereira et al, 2013).

\subsection{Habilidades do Empreendedor}

As habilidades se manifestam no indivíduo através de situações vivenciadas ou executadas pelo mesmo; sendo assim, à medida que o individuo experimenta ocupações diferentes ou semelhantes, as habilidades se manifestam. Maximiano (1995) define habilidades como competências para o desempenho de tarefas, sendo fundamentais para o bom desempenho do empreendedor. Entretanto, alguns autores afirmam que as habilidades, diferentemente do conhecimento, são adquiridas através da experiência (Cielo, 2001).

A busca de oportunidades é a primeira delas, ou seja, é a capacidade que o empreendedor tem de enxergar oportunidades onde outro só vê ameaças, ou seja, competência de ver o que os outros não veem e de visualizar o ausente. O talento de identificar tendências, necessidades atuais e futuras dos clientes são iniciativas igualmente imprescindíveis, conforme Cielo (2001). Assim, cabe ao empreendedor assumir a responsabilidade pessoal pelo desempenho necessário para o alcance de objetivos e metas (Veras, 1999).

\subsection{Motivação Empreendedora}

Dentre tantos perfis de empreendedores, faz-se importante destacar as questões sociais ligadas ao mesmo. Contudo, as mesmas se movimentam por objetivos diversos, e esta motivação deve cumprir o papel de ativar e dirigir o comportamento humano. No âmbito motivacional, um empreendedor é aquele que possui um desejo de independência, autonomia no processo da tomada de decisão (Santos, Caetano \& Curral, 2010).

Segundo Puente (1982), todos os atos têm orientação para o futuro, onde a atividade humana está orientada por planos e projetos, a decisão de aplicar a experiência e conhecimentos adquiridos durante a vida, a possibilidade, as oportunidades existentes. Para McClelland (1972), são os valores, as motivações humanas e a necessidade de autorrealização que movem 
indivíduos na busca de atividades empreendedoras. Entre os principais motivos que impulsionam o indivíduo a agir, situa-se a necessidade de conquistas e realizações.

Quanto às motivações relacionadas ao surgimento de interesses em empreender, Gilad e Levine (1986) apresentam a tese de que há a existência de dois modelos de motivação: a empurrada e a puxada. A empurrada afirma que os empreendedores surgem em decorrência de fatores negativos, como insatisfação no trabalho; perda de emprego; problemas na carreira. Já a motivação puxada argumenta que o surgimento do empreendedor é fruto de fatores positivos, tais como uma potencial lucratividade e sucesso na empreitada. Assim, para Hoeltgebaum, Loesch e Santos (2013), o comportamento depende da maneira como se vive, como se trabalha, de quando se gosta do que se está fazendo.

\section{METODOLOGIA}

Para a elaboração deste trabalho, utilizou-se a metodologia de pesquisa conhecida por exploratória, com o tipo de pesquisa bibliográfica (Cervo \& Bervian, 1996). Gil (1991) apresenta a pesquisa exploratória tendo como objetivo proporcionar maior familiaridade com o problema, com vista a torná-lo mais explícito ou a constituir hipóteses. Seu planejamento é, portanto, bastante flexível, de modo que possibilite a consideração dos mais variados aspectos relativos ao fato estudado.

Ainda, a pesquisa bibliográfica, segundo Rampazzo (2005), tem a finalidade de ampliar o conhecimento na área, de dominar o conhecimento, para depois utilizá-lo como modelo teórico que dará sustentação a outros problemas de pesquisa, e para descrever e sistematizar o estado da arte na área estudada. Quanto a natureza das variáveis, a pesquisa foi quantitativa, que segundo Malhotra (2001), procura quantificar os dados e aplicar alguma forma de análise estatística de caráter exploratório. A coleta de dados realizou-se por meio de entrevista pessoal junto aos alunos do curso de administração no campus avançado de Pitanga. Sendo realizado uma tentativa de censo nos 4 anos do curso, em um total de 100 alunos, no entanto, na impossibilidade de conseguir $100 \%$ dos alunos, fica caracterizada que a amostragem foi não probabilística, aquela em que a seleção dos elementos da população para compor a amostra depende ao menos em parte do julgamento do pesquisador ou do entrevistador no campo por meio de dados primários (Mattar, 1996).

Para obter a cooperação dos entrevistados foi aplicado questionário por conveniência de maneira que deixe o entrevistado à vontade, a fim de garantir que seja feita de modo preciso (Hair, 2005). Para uma melhor qualidade na coleta de dados, não foram utilizadas questões complexas, pois houve autopreenchimento dos alunos, utilizando escala de 5 pontos: "concordo totalmente", "concordo", "nem concordo e nem discordo", "discordo" e "discordo totalmente". Importante destacar que, para fins de teste estatístico, a escala foi agrupada para "concordo totalmente + concordo", "nem concordo e nem discordo", "discordo + discordo totalmente, em 3 pontos.

A análise dos dados foi por meio de estatística descritiva, mediante cruzamento das variáveis faixa etária, ano que cursa e por gênero. Quanto a coleta de dados, realizou-se através de questionários estruturados, não disfarçados, com perguntas fechadas, e como instrumento de coleta de dados houve o pré-teste com 5 entrevistas.

Posteriormente à coleta de dados, os resultados foram tabulados, utilizando-se o Excel; por meio da tabela dinâmica foi possível fazer os cruzamentos nas categorias por sexo, faixa etária, ano do curso, junto as seguintes variáveis: i) se há pretensão de tornar-se um dia um 
empreendedor; ii) se há empreendedor na família; iii) se assumiria risco em um negócio; iv) se empreender tem inspiração em parente e amigos; v) se sente influenciado por cursar administração; vi) se atuaria como empreendedor por questão financeiras; vii) se tem um bom nível de conhecimento de mercado para ser empreendedor e; viii) se gostaria de ser empreendedor em busca de independência e ter os próprios horários de trabalho.

A análise dos dados consistiu em análises univariadas e bivariadas, com base em frequências absolutas e relativas. As medidas de associação foram testadas por meio do teste não paramétrico, o Qui-Quadrado (Siegel \& Castellan, 2006), cuja hipótese da pesquisa é:

H0: Não há diferença significativa quanto a visão empreendedora considerando as variáveis pesquisadas (8) segmentada por sexo, faixa etária e ano do curso do acadêmico.

\section{RESULTADOS E DISCUSSÃO}

A pesquisa foi aplicada junto aos alunos do curso de administração, no campus de Pitanga. Os mesmos responderam a um questionário com perguntas sobre empreendedorismo e sua perspectiva como futuros empreendedores após sua experiência acadêmica. A resposta dada pelos entrevistados segue primeiramente os dados pessoais, no Tabela 1, e logo após os motivos de empreender, composta pelas Tabelas 2 a 10, onde os dados foram cruzados por sexo, faixa etária e ano de curso. As Tabelas 11 e 12 finalizam com o resumo da pesquisa e o teste estatístico não paramétrico Qui Quadrado aplicado para verificar se houve divergências de opiniões entre as categorias estudadas (sexo, faixa etária e ano do curso do acadêmico).

Tabela 1

Perfil do respondente: Faixa etária, ano de curso e gênero

\begin{tabular}{lccccccccc}
\hline & \multicolumn{3}{c}{ Faixa etária vs ano do curso } & \multicolumn{2}{c}{ Ano do curso } & Gênero \\
\hline & 1 Ano & 2 Ano & 3 Ano & 4 Ano & $\%$ & & $\%$ & & $\%$ \\
\hline 17 A 20 & $81 \%$ & $65 \%$ & $42 \%$ & $10 \%$ & $49 \%$ & 1 Ano & $31 \%$ & Feminino & $51 \%$ \\
\hline 21 A 25 & $10 \%$ & $25 \%$ & $37 \%$ & $73 \%$ & $37 \%$ & 2 Ano & $20 \%$ & Masculino & $49 \%$ \\
\hline 25 A 35 & $9 \%$ & $10 \%$ & $21 \%$ & $17 \%$ & $14 \%$ & 3 Ano & $19 \%$ & Total & $100 \%$ \\
\hline Total & $100 \%$ & $100 \%$ & $100 \%$ & $100 \%$ & $100 \%$ & 4 Ano & $30 \%$ & & \\
\cline { 1 - 6 } & & & & & Total & $100 \%$ & & \\
\hline
\end{tabular}

Nota: pesquisa 2018.

O Tabela 1 se refere à faixa etária dos entrevistados, sendo assim, a medida que estão evoluindo no curso de administração, suas idades são maiores, de forma que os alunos do quarto ano estão com idades entre 21 a 25 anos (73\%). Quanto a quantidade de alunos cursando, $31 \%$ dos pesquisados estão cursando o primeiro ano do curso, no entanto, os alunos do quarto ano estão em segundo lugar, com 30\%. Quanto ao gênero, está distribuído para 51\% dos entrevistados mulheres, e $49 \%$ homens.

Tabela 2

Motivo de um dia se tornar empreendedor

\begin{tabular}{lcccccccccc}
\hline & \multicolumn{3}{c}{ Ano } & \multicolumn{3}{c}{ Faixa Etária } & \multicolumn{2}{c}{ Gênero } \\
\hline Um futuro melhor & $\mathbf{1}$ & $\mathbf{2}$ & $\mathbf{3}$ & $\mathbf{4}$ & $\mathbf{1 7 / 2 0}$ & $\mathbf{2 1 / 2 5}$ & $\mathbf{2 5 / 3 5}$ & Fem. & Masc. & Total \\
\hline Ganhar dinheiro & $68 \%$ & $55 \%$ & $58 \%$ & $40 \%$ & $67 \%$ & $46 \%$ & $45 \%$ & $61 \%$ & $49 \%$ & $55 \%$ \\
\hline Gerar emprego/renda & $29 \%$ & $40 \%$ & $37 \%$ & $57 \%$ & $31 \%$ & $46 \%$ & $55 \%$ & $37 \%$ & $45 \%$ & $41 \%$ \\
\hline Total & $3 \%$ & $5 \%$ & $5 \%$ & $3 \%$ & $2 \%$ & $8 \%$ & $0 \%$ & $2 \%$ & $6 \%$ & $4 \%$ \\
\hline Nota: pesquisa 2018. & $100 \%$ & $100 \%$ & $100 \%$ & $100 \%$ & $100 \%$ & $100 \%$ & $100 \%$ & $100 \%$ & $100 \%$ & $100 \%$ \\
\hline
\end{tabular}

UFAMBR, Manaus, v. 1, n.1, art. 1, pp. 01-17, janeiro-junho, 2019 http://www.periodicos.ufam.edu.br/ufambr 
A Tabela 2 tem por objetivo analisar o motivo pelo qual o aluno iria empreender, entre os quesitos mais relatados foram "ter um futuro melhor" e "ganhar dinheiro", com 55\% e 41\% respectivamente, evidenciando que a questão "ganhar dinheiro" foi mais mencionada entre os alunos com idade acima de 25 (55\%), enquanto os mais jovens (até 20 anos) aparece com $67 \%$ de citação de "ter um futuro melhor".

Observando a questão, fica evidenciada a forma de competência, ou seja, ações evidenciadas e associadas, formando-se assim uma identificação de oportunidade; segundo Mamede e Moreira (2005), a competência empreendedora pode ser tratada tanto como competência do indivíduo, quanto relacionada à prática administrativa, devido às diferentes tarefas que desempenham, e isto pode estar associado ao avançar da idade.

Tabela 3

Tenho a pretensão de, um dia, tornar-me dia um empreendedor

\begin{tabular}{|c|c|c|c|c|c|c|c|c|c|c|}
\hline & \multicolumn{4}{|c|}{ Ano do curso } & \multicolumn{3}{|c|}{ Faixa etária } & \multicolumn{2}{|c|}{ Gênero } & \multirow[b]{2}{*}{ Total } \\
\hline & 1 & 2 & 3 & 4 & $17 / 20$ & $21 / 25$ & $25 / 35$ & Fem. & Masc. & \\
\hline Concordo totalmente & $42 \%$ & $50 \%$ & $36 \%$ & $17 \%$ & $45 \%$ & $14 \%$ & $73 \%$ & $33 \%$ & $37 \%$ & $35 \%$ \\
\hline Concordo & $55 \%$ & $45 \%$ & $37 \%$ & $37 \%$ & $45 \%$ & $54 \%$ & $18 \%$ & $43 \%$ & $45 \%$ & $44 \%$ \\
\hline $\begin{array}{l}\text { Nem concordo/ } \\
\text { Nem discordo }\end{array}$ & $0 \%$ & $5 \%$ & $11 \%$ & $30 \%$ & $6 \%$ & $19 \%$ & $0 \%$ & $12 \%$ & $12 \%$ & $12 \%$ \\
\hline Discordo & $0 \%$ & $0 \%$ & $5 \%$ & $10 \%$ & $0 \%$ & $8 \%$ & $9 \%$ & $6 \%$ & $2 \%$ & $4 \%$ \\
\hline Discordo totalmente & $3 \%$ & $0 \%$ & $11 \%$ & $3 \%$ & $4 \%$ & $3 \%$ & $0 \%$ & $4 \%$ & $4 \%$ & $4 \%$ \\
\hline Total geral & $100 \%$ & $100 \%$ & $100 \%$ & $100 \%$ & $100 \%$ & $100 \%$ & $100 \%$ & $100 \%$ & $100 \%$ & $100 \%$ \\
\hline
\end{tabular}

Nota: pesquisa 2018

A Tabela 3 aponta se, de fato, os acadêmicos do campus de Pitanga têm o intuito de abrir seu próprio negócio futuramente. Desta forma, de maneira bastante evidente, entre os acadêmicos que estão cursando o primeiro ano $(42 \%)$ e o segundo ano $(50 \%)$ há maior índice de "concordo totalmente". No entanto, índice de maior concordância (73\%) está entre os acadêmicos acima dos 25 anos. Custódio (2011) esclarece que nem todo empreendedor é um empresário, então, o ideal é ser empresário empreendedor, o que pode facilitar a sobrevivência no mundo dos negócios.

Tabela 4

Tenho histórico de empreendedor em minha família

\begin{tabular}{|c|c|c|c|c|c|c|c|c|c|c|}
\hline & \multicolumn{4}{|c|}{ Ano do curso } & \multicolumn{3}{|c|}{ Faixa Etária } & \multicolumn{2}{|c|}{ Gênero } & \multirow[b]{2}{*}{ Total } \\
\hline & 1 & 2 & 3 & 4 & $17 / 20$ & $21 / 25$ & $25 / 35$ & Fem. & Masc. & \\
\hline Concordo Totalmente & $16 \%$ & $15 \%$ & $21 \%$ & $7 \%$ & $14 \%$ & $11 \%$ & $27 \%$ & $16 \%$ & $12 \%$ & $14 \%$ \\
\hline Concordo & $42 \%$ & $30 \%$ & $5 \%$ & $17 \%$ & $39 \%$ & $14 \%$ & $0 \%$ & $18 \%$ & $33 \%$ & $25 \%$ \\
\hline $\begin{array}{l}\text { Nem concordo/ } \\
\text { Nem discordo }\end{array}$ & $23 \%$ & $15 \%$ & $26 \%$ & $27 \%$ & $18 \%$ & $30 \%$ & $27 \%$ & $22 \%$ & $24 \%$ & $23 \%$ \\
\hline Discordo & $13 \%$ & $35 \%$ & $26 \%$ & $33 \%$ & $18 \%$ & $35 \%$ & $36 \%$ & $31 \%$ & $20 \%$ & $26 \%$ \\
\hline Discordo Totalmente & $6 \%$ & $5 \%$ & $21 \%$ & $17 \%$ & $10 \%$ & $11 \%$ & $9 \%$ & $14 \%$ & $10 \%$ & $12 \%$ \\
\hline Total & $100 \%$ & $100 \%$ & $100 \%$ & $100 \%$ & $100 \%$ & $100 \%$ & $100 \%$ & $100 \%$ & $100 \%$ & $100 \%$ \\
\hline
\end{tabular}

Nota: pesquisa 2018

A Tabela 4 tem o intuito de analisar se há empreendedores na família, assim é possível saber se ocorre alguma influência em se tornar um empreendedor no futuro. De acordo com os resultados, pode-se confirmar as informações, que os acadêmicos do primeiro ano (58\%) e segundo ano (45\%), mostram um percentual maior sobre a questão de empreendedores na família, podendo, dessa forma, serem influenciados pelo sucesso de seus familiares, etc, 
considerando as respostas "concordo totalmente" e "concordo". O aspecto forte deve ser evidenciando quando o empreendedor é herdeiro, pois há decisão de dar continuidade aos negócios da família de modo eficiente e eficaz, pois o empreendedor herdeiro recebe logo cedo a missão de levar à frente o legado de sua família, com o desafio de multiplicar o patrimônio recebido (Pereira et al, 2013).

Tabela 5

\section{Assumiria risco de um empreendimento mesmo que não tenha total conhecimento do} negócio

\begin{tabular}{lcccccccccc}
\hline & \multicolumn{3}{c}{ Ano do curso } & \multicolumn{3}{c}{ Faixa Etária } & \multicolumn{2}{c}{ Gênero } \\
\hline & $\mathbf{1}$ & $\mathbf{2}$ & $\mathbf{3}$ & $\mathbf{4}$ & $\mathbf{1 7 / 2 0}$ & $\mathbf{2 1 / 2 5}$ & $\mathbf{2 5 / 3 5}$ & Fem. & Masc. & Total \\
\hline Concordo Totalmente & $0 \%$ & $5 \%$ & $5 \%$ & $0 \%$ & $2 \%$ & $0 \%$ & $9 \%$ & $2 \%$ & $2 \%$ & $2 \%$ \\
\hline Concordo & $29 \%$ & $30 \%$ & $26 \%$ & $10 \%$ & $27 \%$ & $19 \%$ & $27 \%$ & $20 \%$ & $27 \%$ & $23 \%$ \\
\hline $\begin{array}{l}\text { Nem concordo/ } \\
\text { Nem discordo }\end{array}$ & $19 \%$ & $35 \%$ & $26 \%$ & $23 \%$ & $27 \%$ & $22 \%$ & $36 \%$ & $25 \%$ & $24 \%$ & $25 \%$ \\
\hline Discordo & $45 \%$ & $25 \%$ & $21 \%$ & $37 \%$ & $39 \%$ & $35 \%$ & $9 \%$ & $35 \%$ & $33 \%$ & $34 \%$ \\
\hline Discordo Totalmente & $6 \%$ & $0 \%$ & $21 \%$ & $27 \%$ & $4 \%$ & $24 \%$ & $9 \%$ & $18 \%$ & $10 \%$ & $14 \%$ \\
\hline Total Geral & $100 \%$ & $100 \%$ & $100 \%$ & $100 \%$ & $100 \%$ & $100 \%$ & $100 \%$ & $100 \%$ & $100 \%$ & $100 \%$ \\
\hline Nota: pesquisa 2018 & & & & & & & & & &
\end{tabular}

A Tabela 5 tem o objetivo de avaliar a capacidade de avaliação e o interesse dos acadêmicos em empreender em um negócio que possa dar errado. Percebe-se que entre os entrevistados fica evidenciado que apenas $25 \%$ dos entrevistados não assumiriam esse risco, estando assim consciente do risco de assumir algo incerto, na escala "concordo totalmente" e "concordo".

Para Bruyat e Julien (2000), empreendedor é o indivíduo responsável pelo processo de criação de uma nova empresa, após a criação da empresa existe uma constante troca de experiências e informações entre o indivíduo e o novo valor criado. De acordo com Henderson (2002), apesar de possuírem características peculiares, como assumir grandes riscos, ser inovador é procurar construir vantagens competitivas.

Tabela 6

Minha vontade de empreender sempre existiu e é inspirada por parentes e amigos

\begin{tabular}{lcccccccccc}
\hline & \multicolumn{3}{c}{ Ano do curso } & \multicolumn{4}{c}{ Faixa Etária } & \multicolumn{2}{c}{ Gênero } \\
\hline & $\mathbf{1}$ & $\mathbf{2}$ & $\mathbf{3}$ & $\mathbf{4}$ & $\mathbf{1 7 / 2 0}$ & $\mathbf{2 1 / 2 5}$ & $\mathbf{2 5 / 3 5}$ & Fem. & Masc. & Total \\
\hline Concordo Totalmente & $3 \%$ & $20 \%$ & $21 \%$ & $3 \%$ & $6 \%$ & $14 \%$ & $18 \%$ & $12 \%$ & $8 \%$ & $10 \%$ \\
\hline Concordo & $48 \%$ & $30 \%$ & $16 \%$ & $17 \%$ & $41 \%$ & $14 \%$ & $27 \%$ & $22 \%$ & $37 \%$ & $29 \%$ \\
\hline Nem concordo/ & & & & & & & & & & \\
Nem discordo & $26 \%$ & $30 \%$ & $26 \%$ & $37 \%$ & $24 \%$ & $30 \%$ & $55 \%$ & $27 \%$ & $33 \%$ & $30 \%$ \\
\hline Discordo & $13 \%$ & $15 \%$ & $32 \%$ & $37 \%$ & $22 \%$ & $35 \%$ & $0 \%$ & $33 \%$ & $14 \%$ & $24 \%$ \\
\hline Discordo Totalmente & $10 \%$ & $5 \%$ & $5 \%$ & $7 \%$ & $6 \%$ & $8 \%$ & $0 \%$ & $6 \%$ & $8 \%$ & $7 \%$ \\
\hline Total & $100 \%$ & $100 \%$ & $100 \%$ & $100 \%$ & $100 \%$ & $100 \%$ & $100 \%$ & $100 \%$ & $100 \%$ & $100 \%$ \\
\hline Nota
\end{tabular}

Nota: pesquisa 2018

A Tabela 6 tem o propósito de observar o quanto os parentes e amigos de modo geral influenciam na convivência dos acadêmicos entrevistados. Assim, os resultados apontam que os alunos do primeiro (51\%) e segundo ano (50\%), são motivados por parentes e amigos, na escala "concordo totalmente" e "concordo". Moore e Buttner (1997) afirmam que um fator que pode indiretamente exercer influência na decisão de abrir uma empresa é a existência de modelos de referência, no caso de sucesso familiar e pessoas próximas. Segundo Murray (1973), crianças motivadas por suas mães deram resultados mais positivos quando se tornaram adultos e empresários. 
Tabela 7

Sinto-me influenciado em empreender por estar cursando Administração

\begin{tabular}{lcccccccccc}
\hline & \multicolumn{3}{c}{ Ano do curso } & \multicolumn{3}{c}{ Faixa Etária } & \multicolumn{2}{c}{ Gênero } \\
\hline & $\mathbf{1}$ & $\mathbf{2}$ & $\mathbf{3}$ & $\mathbf{4}$ & $\mathbf{1 7 / 2 0}$ & $\mathbf{2 1 / 2 5}$ & $\mathbf{2 5 / 3 5}$ & Fem. & Masc. & Total \\
\hline Concordo Totalmente & $13 \%$ & $35 \%$ & $21 \%$ & $20 \%$ & $20 \%$ & $19 \%$ & $27 \%$ & $22 \%$ & $20 \%$ & $21 \%$ \\
\hline Concordo & $58 \%$ & $45 \%$ & $42 \%$ & $37 \%$ & $51 \%$ & $41 \%$ & $55 \%$ & $47 \%$ & $45 \%$ & $46 \%$ \\
\hline Nem concordo/ & & & & & & & & & & \\
Nem discordo & $13 \%$ & $20 \%$ & $26 \%$ & $27 \%$ & $22 \%$ & $22 \%$ & $9 \%$ & $20 \%$ & $22 \%$ & $21 \%$ \\
\hline Discordo & $6 \%$ & $0 \%$ & $11 \%$ & $17 \%$ & $6 \%$ & $16 \%$ & $0 \%$ & $10 \%$ & $8 \%$ & $9 \%$ \\
\hline Discordo Totalmente & $10 \%$ & $0 \%$ & $0 \%$ & $0 \%$ & $0 \%$ & $3 \%$ & $9 \%$ & $2 \%$ & $4 \%$ & $3 \%$ \\
\hline Total Geral & $100 \%$ & $100 \%$ & $100 \%$ & $100 \%$ & $100 \%$ & $100 \%$ & $100 \%$ & $100 \%$ & $100 \%$ & $100 \%$ \\
\hline Nota: pesquisa 2018 & & & & & & & & &
\end{tabular}

A Tabela 7 tem objetivo de analisar o quanto os acadêmicos estão motivados a empreender pelo fato de estar cursando administração, o quanto o curso está influenciando e ampliando seus conhecimentos. Os acadêmicos apresentam índice de $67 \%$ de concordância (concordo totalmente + concordo), sendo predominante entre alunos do segundo ano do curso, com $70 \%$, e entre aqueles com idades entre 25 e 35 anos, totalizando $82 \%$. Isso indica que a sociedade contemporânea exige pessoas empreendedoras, autônomas, com competências múltiplas, que tenham capacidade de aprender, e adaptar-se a situações novas e promover transformações (SEBRAE, 2017).

Tabela 8

Atuaria em algum empreendimento por necessidade financeira

\begin{tabular}{|c|c|c|c|c|c|c|c|c|c|c|}
\hline & \multicolumn{4}{|c|}{ Ano do curso } & \multicolumn{3}{|c|}{ Faixa Etária } & \multicolumn{2}{|c|}{ Gênero } & \multirow[b]{2}{*}{ Total } \\
\hline & 1 & 2 & 3 & 4 & $17 / 20$ & $21 / 25$ & $25 / 35$ & Fem. & Masc. & \\
\hline Concordo Totalmente & $13 \%$ & $25 \%$ & $16 \%$ & $27 \%$ & $18 \%$ & $19 \%$ & $27 \%$ & $10 \%$ & $31 \%$ & $20 \%$ \\
\hline Concordo & $52 \%$ & $60 \%$ & $47 \%$ & $43 \%$ & $51 \%$ & $57 \%$ & $36 \%$ & $53 \%$ & $47 \%$ & $50 \%$ \\
\hline $\begin{array}{l}\text { Nem concordo/ } \\
\text { Nem discordo }\end{array}$ & $29 \%$ & $15 \%$ & $32 \%$ & $13 \%$ & $29 \%$ & $11 \%$ & $27 \%$ & $31 \%$ & $12 \%$ & $22 \%$ \\
\hline Discordo & $6 \%$ & $0 \%$ & $5 \%$ & $10 \%$ & $2 \%$ & $11 \%$ & $9 \%$ & $4 \%$ & $8 \%$ & $6 \%$ \\
\hline Discordo Totalmente & $0 \%$ & $0 \%$ & $0 \%$ & $3 \%$ & $0 \%$ & $0 \%$ & $0 \%$ & $0 \%$ & $2 \%$ & $1 \%$ \\
\hline Total Geral & $100 \%$ & $100 \%$ & $100 \%$ & $100 \%$ & $100 \%$ & $100 \%$ & $100 \%$ & $100 \%$ & $100 \%$ & $100 \%$ \\
\hline
\end{tabular}

Nota: pesquisa 2018,

A Tabela 8 demonstra se os acadêmicos têm pretensão em abrir seu negócio próprio, em alguma fase ruim da vida; ou seja, abrir seu negócio por necessidade financeira. De acordo com as resposta dos acadêmicos, 70\% "concordam totalmente" e "concordam" com esse cenário, cujos maiores indicadores estão entre os alunos do segundo ano, com 85\% de citação.

Tabela 9

Tenho um bom nível de conhecimento (estudo) de mercado caso fosse empreender

\begin{tabular}{|c|c|c|c|c|c|c|c|c|c|c|}
\hline & \multicolumn{4}{|c|}{ Ano do curso } & \multicolumn{3}{|c|}{ Faixa Etária } & \multicolumn{2}{|c|}{ Gênero } & \multirow[b]{2}{*}{ Total } \\
\hline & 1 & 2 & 3 & 4 & $17 / 20$ & $21 / 25$ & $25 / 35$ & Fem. & Masc. & \\
\hline Concordo Totalmente & $3 \%$ & $5 \%$ & $21 \%$ & $10 \%$ & $8 \%$ & $5 \%$ & $18 \%$ & $8 \%$ & $10 \%$ & $9 \%$ \\
\hline Concordo & $29 \%$ & $35 \%$ & $26 \%$ & $47 \%$ & $29 \%$ & $38 \%$ & $55 \%$ & $29 \%$ & $41 \%$ & $35 \%$ \\
\hline $\begin{array}{l}\text { Nem concordo/ } \\
\text { Nem discordo }\end{array}$ & $39 \%$ & $55 \%$ & $42 \%$ & $37 \%$ & $43 \%$ & $49 \%$ & $27 \%$ & $43 \%$ & $41 \%$ & $42 \%$ \\
\hline Discordo & $19 \%$ & $5 \%$ & $11 \%$ & $3 \%$ & $16 \%$ & $5 \%$ & $0 \%$ & $14 \%$ & $6 \%$ & $10 \%$ \\
\hline Discordo Totalmente & $10 \%$ & $0 \%$ & $0 \%$ & $3 \%$ & $4 \%$ & $3 \%$ & $0 \%$ & $6 \%$ & $2 \%$ & $4 \%$ \\
\hline Total Geral & $100 \%$ & $100 \%$ & $100 \%$ & $100 \%$ & $100 \%$ & $100 \%$ & $100 \%$ & $100 \%$ & $100 \%$ & $100 \%$ \\
\hline
\end{tabular}


A Tabela 9 objetiva registrar o quanto os acadêmicos se encontram aptos quanto ao seu nível de conhecimento já adquiridos durante o curso de administração. Assim, os alunos do quarto ano, com 57\%, "concordam totalmente" e "concordam" com essa afirmação. Esse indicador é maior entre os homens, com 51\%. Machado et al. (2003) citam alguns fatores ligados à decisão de iniciar um empreendimento, independentemente do gênero, dentre os quais se destacam a experiência profissional anterior e a existência de modelos empreendedores na família.

Tabela 10

Gostaria de empreender em busca de independência e ter meus próprios horários

\begin{tabular}{lcccccccccc}
\hline & & \multicolumn{3}{c}{ Ano do curso } & \multicolumn{3}{c}{ Faixa Etária } & \multicolumn{2}{c}{ Gênero } \\
\hline & $\mathbf{1}$ & $\mathbf{2}$ & $\mathbf{3}$ & $\mathbf{4}$ & $\mathbf{1 7 / 2 0}$ & $\mathbf{2 1 / 2 5}$ & $\mathbf{2 5 / 3 5}$ & Fem. & Masc. & Total \\
\hline Concorda Totalmente & $35 \%$ & $30 \%$ & $26 \%$ & $33 \%$ & $31 \%$ & $24 \%$ & $55 \%$ & $29 \%$ & $35 \%$ & $32 \%$ \\
\hline Concorda & $48 \%$ & $45 \%$ & $47 \%$ & $43 \%$ & $47 \%$ & $51 \%$ & $27 \%$ & $43 \%$ & $49 \%$ & $46 \%$ \\
\hline $\begin{array}{l}\text { Nem concordo/ } \\
\text { Nem discordo }\end{array}$ & $13 \%$ & $20 \%$ & $11 \%$ & $20 \%$ & $12 \%$ & $22 \%$ & $18 \%$ & $20 \%$ & $12 \%$ & $16 \%$ \\
\hline Discorda & $3 \%$ & $5 \%$ & $5 \%$ & $3 \%$ & $6 \%$ & $3 \%$ & $0 \%$ & $4 \%$ & $4 \%$ & $4 \%$ \\
\hline Discordo Totalmente & $0 \%$ & $0 \%$ & $11 \%$ & $0 \%$ & $4 \%$ & $0 \%$ & $0 \%$ & $4 \%$ & $0 \%$ & $2 \%$ \\
\hline Total & $100 \%$ & $100 \%$ & $100 \%$ & $100 \%$ & $100 \%$ & $100 \%$ & $100 \%$ & $100 \%$ & $100 \%$ & $100 \%$ \\
\hline Nota: pesquisa 2018 & & & & & & & & & &
\end{tabular}

Nota: pesquisa 2018

A Tabela 10 apresenta o desejo dos acadêmicos de empreender com a intenção de fazer seus próprios horários e, consequentemente, ter mais autonomia financeira. De forma geral, $78 \%$ dos acadêmicos "concordam totalmente" e "concordam" com essa afirmação. O índice é maior entre os homens (82\%) e alunos do primeiro ano (83\%). De acordo com Henderson (2002), os iniciantes a empreendedores buscam independência com seus próprios horários, que por vez sacrificam o crescimento de seu negócio por suas escolhas relacionadas ao seu estilo de vida.

Em resumo, apresentam-se os resultados do presente estudo, conforme Tabela 11, cujo indicador de maior concordância na escala "concordo totalmente" e "concordo" é para a ideia de ser um dia empreendedor (Tabela 3), com 79\%, seguido com o propósito de que ser empreendedor é partir em busca de independência e ter os próprios horários, com $78 \%$ (Tabela 10). Destaca-se que, conforme a Tabela 5, apenas $25 \%$ dos acadêmicos estarem dispostos a assumir o risco de um empreendimento onde não tenham total conhecimento do negócio (Tabela 5).

Tabela 11

Resumo dos resultados da pesquisa

\begin{tabular}{|c|c|c|c|c|c|}
\hline & $\begin{array}{c}\text { Concordo } \\
\text { totalmente }\end{array}$ & Concordo & $\begin{array}{l}\text { Nem concordo } \\
\text { Nem discordo }\end{array}$ & Discordo & $\begin{array}{l}\text { Discordo } \\
\text { totalmente }\end{array}$ \\
\hline $\begin{array}{l}\text { Tabela 3: } \\
\text { Tenho a pretensão de tornar-me um } \\
\text { dia um empreendedor }\end{array}$ & $35 \%$ & $44 \%$ & $12 \%$ & $4 \%$ & $4 \%$ \\
\hline $\begin{array}{l}\text { Tabela 4: } \\
\text { Tenho histórico de empreendedor } \\
\text { em minha família }\end{array}$ & $14 \%$ & $25 \%$ & $23 \%$ & $26 \%$ & $12 \%$ \\
\hline $\begin{array}{l}\text { Tabela 5: } \\
\text { Assumiria risco de um } \\
\text { empreendimento mesmo que não } \\
\text { tenha total conhecimento do } \\
\text { negócio }\end{array}$ & $2 \%$ & $23 \%$ & $25 \%$ & $34 \%$ & $14 \%$ \\
\hline
\end{tabular}




\begin{tabular}{|c|c|c|c|c|c|}
\hline $\begin{array}{l}\text { Tabela 6: } \\
\text { Minha vontade de empreender } \\
\text { sempre existiu e é inspirada por } \\
\text { parentes e amigos }\end{array}$ & $10 \%$ & $29 \%$ & $30 \%$ & $24 \%$ & $7 \%$ \\
\hline $\begin{array}{l}\text { Tabela 7: } \\
\text { Sinto-me influenciado a } \\
\text { empreender por estar cursando } \\
\text { administração }\end{array}$ & $21 \%$ & $46 \%$ & $21 \%$ & $9 \%$ & $3 \%$ \\
\hline $\begin{array}{l}\text { Tabela 8: } \\
\text { Atuaria em algum empreendimento } \\
\text { por necessidade financeira }\end{array}$ & $20 \%$ & $50 \%$ & $22 \%$ & $6 \%$ & $1 \%$ \\
\hline $\begin{array}{l}\text { Tabela 9: } \\
\text { Tenho um bom nível de } \\
\text { conhecimento (estudo) de mercado } \\
\text { caso fosse empreender }\end{array}$ & $9 \%$ & $35 \%$ & $42 \%$ & $10 \%$ & $4 \%$ \\
\hline $\begin{array}{l}\text { Tabela 10: } \\
\text { Gostaria de empreender em busca } \\
\text { de independência e ter meus } \\
\text { próprios horários }\end{array}$ & $32 \%$ & $46 \%$ & $16 \%$ & $4 \%$ & $2 \%$ \\
\hline
\end{tabular}

Nota: pesquisa 2018

De acordo com a Tabela 12, aponta-se os resultados da hipótese para o teste estatístico, o Qui Quadrado, em que deve ser rejeitado a hipótese H0 para as variáveis ao nível de significância de $5 \%$, uma vez que se verificou diferenças de opiniões entre os grupos pesquisados para as variáveis:

"Tenho a pretensão de tornar-me um dia um empreendedor", com destaque junto aos acadêmicos do primeiro e segundo ano (Tabela 3 ).

"Atuaria em algum empreendimento por necessidade financeira", com destaque junto aos acadêmicos do gênero masculino (Tabela 8).

Tabela 12

Resumo do teste estatístico não paramétrico: Qui Quadrado

\begin{tabular}{|c|c|c|c|c|c|c|}
\hline & P-valor & $\begin{array}{c}\text { Teste hipótese - } \\
\text { Ano curso }\end{array}$ & P-valor & $\begin{array}{c}\text { Teste hipótese - } \\
\text { Faixa etária } \\
\end{array}$ & P-valor & $\begin{array}{c}\text { Teste hipótese - } \\
\text { Gênero }\end{array}$ \\
\hline $\begin{array}{l}\text { Tabela 2: } \\
\text { Motivo de um dia se } \\
\text { tornar empreendedor }\end{array}$ & 0,50 & $\begin{array}{l}\text { Aceita a hipótese } \\
\text { H0 }\end{array}$ & 0,08 & $\begin{array}{l}\text { Aceita a hipótese } \\
\text { H0 }\end{array}$ & 0,36 & $\begin{array}{l}\text { Aceita a hipótese } \\
\text { H0 }\end{array}$ \\
\hline $\begin{array}{l}\text { Tabela 3: } \\
\text { Tenho a pretensão de } \\
\text { tornar-me um dia um } \\
\text { empreendedor }\end{array}$ & $0,00 * *$ & $\begin{array}{l}\text { Rejeita a } \\
\text { hipótese H0 }\end{array}$ & 0,14 & $\begin{array}{l}\text { Aceita a hipótese } \\
\text { H0 }\end{array}$ & 0,61 & $\begin{array}{l}\text { Aceita a hipótese } \\
\text { H0 }\end{array}$ \\
\hline $\begin{array}{l}\text { Tabela 4: } \\
\text { Tenho histórico de } \\
\text { empreendedor em minha } \\
\text { família }\end{array}$ & 0,09 & $\begin{array}{l}\text { Aceita a hipótese } \\
\text { H0 }\end{array}$ & 0,08 & $\begin{array}{l}\text { Aceita a hipótese } \\
\text { H0 }\end{array}$ & 0,31 & $\begin{array}{l}\text { Aceita a hipótese } \\
\text { H0 }\end{array}$ \\
\hline $\begin{array}{l}\text { Tabela 5: } \\
\text { Assumiria risco de um } \\
\text { empreendimento mesmo } \\
\text { que não tenha total } \\
\text { conhecimento do negócio }\end{array}$ & 0,19 & $\begin{array}{l}\text { Aceita a hipótese } \\
\text { H0 }\end{array}$ & 0,87 & $\begin{array}{l}\text { Aceita a hipótese } \\
\text { H0 }\end{array}$ & 0,43 & $\begin{array}{l}\text { Aceita a hipótese } \\
\text { H0 }\end{array}$ \\
\hline $\begin{array}{l}\text { Tabela 6: } \\
\text { Minha vontade de } \\
\text { empreender sempre } \\
\text { existiu e é inspirada por } \\
\text { parentes e amigos }\end{array}$ & 0,20 & $\begin{array}{l}\text { Aceita a hipótese } \\
\text { H0 }\end{array}$ & 0,06 & $\begin{array}{l}\text { Aceita a hipótese } \\
\text { H0 }\end{array}$ & 0,19 & $\begin{array}{l}\text { Aceita a hipótese } \\
\text { H0 }\end{array}$ \\
\hline $\begin{array}{l}\text { Tabela 7: } \\
\text { Sinto-me influenciado em }\end{array}$ & 0,40 & $\begin{array}{l}\text { Aceita a hipótese } \\
\text { HO }\end{array}$ & & $\begin{array}{l}\text { Aceita a hipótese } \\
\text { H0 }\end{array}$ & 0,93 & $\begin{array}{l}\text { Aceita a hipótese } \\
\text { H0 }\end{array}$ \\
\hline
\end{tabular}




\begin{tabular}{|c|c|c|c|c|c|c|}
\hline $\begin{array}{l}\text { empreender por estar } \\
\text { cursando administração }\end{array}$ & & & 0,43 & & & \\
\hline $\begin{array}{l}\text { Tabela 8: } \\
\text { Atuaria em algum } \\
\text { empreendimento por } \\
\text { necessidade financeira }\end{array}$ & 0,39 & $\begin{array}{l}\text { Aceita a hipótese } \\
\text { H0 }\end{array}$ & 0,17 & $\begin{array}{l}\text { Aceita a hipótese } \\
\text { H0 }\end{array}$ & $0,03 * *$ & $\begin{array}{l}\text { Rejeita a hipótese } \\
\text { H0 }\end{array}$ \\
\hline
\end{tabular}

Tabela 9:

Tenho um bom nível de conhecimento (estudo) de mercado caso fosse empreender

Tabela 10:

Gostaria de empreender em busca de independência e ter meus próprios horários

Nota: autores (2018) - significativo a $5 \%(\mathrm{p}<0,05) * *$

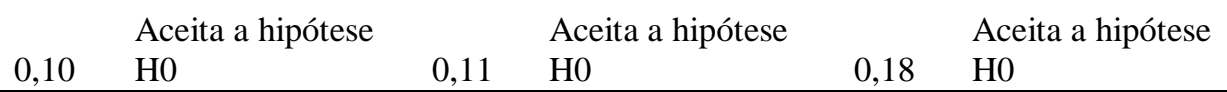

\section{CONCLUSÃO}

O presente trabalho procurou identificar a opinião e a atitude dos estudantes de Pitanga, do curso de administração da Unicentro, a respeito de sua visão empreendedora, salientando assim o desejo que os mesmo possuem de empreender em seus próprios negócios, cujos objetivos entende-se que foram alcançados na pesquisa.

Comprova-se o primeiro objetivo específico ao verificar se existe alguma influência pelo fato de ser aluno de administração, pois, com base na pesquisa, $79 \%$ concordam com essa afirmação.

Ao levantar a intenção de um dia torna-se empreendedor; ficou sugerido que desejam empreender e determinar seu futuro próximo, com 55\% de citação, e $41 \%$ relataram que desejam ganhar dinheiro. Sugere-se que os resultados apontados têm em vista que os dois motivos relatados caminham juntos

Quanto ao fato de possuírem empreendedores na família, os acadêmicos discordam, com 26\%; no entanto, outra parcela dos acadêmicos concorda com o fato de possuírem empreendedores. Mesmo que seja pouca a diferença, traz consigo alguma forma de influência na vida, talvez por alguma motivação devido ao sucesso de seus familiares e amigos próximos.

Ao levantar os motivos pelas quais desejaria ser um empreendedor, os acadêmicos relataram a busca pelos seus próprios horários, o anseio de obter seu horário para trabalho diferenciado (78\%); certamente ocorre a aspiração de se tornar dono de seu próprio negócio.

Ao comparar resultados obtidos com pesquisas realizados no Campus de Santa Cruz, apontase que $40 \%$ dos participantes consideram-se empreendedores, enquanto, entre os participantes de Pitanga houve um índice de $36 \%$; e quanto a haver empreendedores na família, o campus Santa Cruz apontou 54\% de concordância, já no campus de Pitanga aparece com apenas $23 \%$.

A limitação da pesquisa é que não pode ser generalizada, pois realizou-se apenas em uma instituição pública, campus avançado na cidade de Pitanga, e foi possível comparar apenas 2 variáveis com a pesquisa no campus Santa Cruz. Pesquisas em outras instituições podem 
apresentar outros resultados, como no campus de Irati, porém, por outro lado, este estudo pode auxiliar no desenvolvimentos de estudo sobre temas semelhantes.

Como contribuição da pesquisa, entende-se que mostra para a sociedade que o empreendedorismo atua com a geração de empregos, expandindo a economia, e que alunos de graduação em administração podem encontrar essa vocação.

Para pesquisas futuras, sugere-se que sejam baseadas em amostragens probabilísticas que permitam expandir as contribuições iniciais do estudo, pois o presente trabalho não deve ser considerado por encerrado, apenas como uma base para outros estudos futuros, podendo ser adaptado conforme as necessidades de pesquisadores que desejem um maior aprofundamento no assunto.

\section{REFERÊNCIAS}

Bride, J. V., \& Bidinotto, G. (2009) Empreendedorismo e metodologia. Centro Universitário Leonardo da Vinci.

Bruyat, C., \& Julien, P. (2000) Defining the field of research inentrepreneurship. Journal of Business Venturing, v.16, p. 165-180.

Cervo, A. L., \& Bervian, P. A. (1996) Metodologia científica. São Paulo: Makron Books.

Cielo, I. D. (2001) Perfil do empreendedor: uma investigação das características empreendedoras nas empresas de pequena dimensão. Disponível em: <https://repositorio.ufsc.br/xmlui/handle/123456789/79812>. Acesso em: 04 mar. 2018 .

Custódio, T. P. (2011)A importância do empreendedorismo como estratégia de negócio.2011. Disponível em: <http://www.unisalesiano.edu.br/biblioteca/monografias/53972.pdf >. Acesso em: 14 jan. 2018.

Degen, R. (1989) O empreendedor: fundamentos da iniciativa empresarial. São Paulo: McGrow-Hill.

Dornelas, J. C. A. (2007) Empreendedorismo na prática: Mitos e verdades do empreendedor de sucesso. Rio de Janeiro: Elsevier.

Dornelas, J. C. A. (2009) Empreendedorismo. 3 ed. Rio de Janeiro.

Dornelas, J. C. A. (2001) Empreendedorismo: transformando ideias em negócios. Rio de Janeiro: Elsevier.

Filion, L. J. (1999) Empreendedorismo: empreendedores e proprietários-gerentesde pequenos negócios. Revista de administração, v. 34, n. 2, p. 5-28.

Filion, L., \& Dolabela, F. (2000) Boa Ideia! E agora: plano de negócio, o caminho seguro para criar e gerenciar sua empresa: $1^{\mathrm{a}} \mathrm{ed}$. São Paulo: Editora Cultura.

Freire, A. (2005) Paixão por empreender. Rio de Janeiro: Elsevier.

Gil, A. C. (1991) Como elaborar projetos de pesquisa. São Paulo: Atlas. 
Gilad B., \& Levine P. A (1986) Behavioral model of entrepreneurial supply. Journal of Small Business Management. Outubro.

Hair et al. (2005) Fundamentos de métodos de pesquisa em administração. Porto Alegre: Bookman

Henderson, J. (2002) Building the rural economy with high. Growth entrepreneurs,.

Hisrich, R., \& Peters, M. (2004) Empreendedorismo: 5ª ed. Porto Alegre: Editora Bookman.

Hoeltgebaum, M, Loesch, C., \& Santos, R. (2013) Motivações que levam ao empreendedorismo versus satisfação com o desempenho organizacional: um estudo na indústria têxtil de Blumenau. 2013. Disponível em: <http://www.anegepe.org.br/edicoesanteriores/brasilia/[09].pdf>. Acesso em: 14 jan. 2018.

Kiggundu, M. (2002) Entrepreneurs and entrepreneurship in Africa: What is known and what needs to be done. Journal of Development Entrepreneurship, v. 7, n. 3, p. 239-258.

Machado, H. P. V. et al. (2003) O processo de criação de empresas por mulheres. RAEEletrônica, v. 2, n. 2, jul./dez.

Malhotra, N. K. (2001) Pesquisa de marketing: uma orientação aplicada. 3 ed. Porto Alegre: Bookman.

Mamede, M. I. B., \& Moreira, M. Z. (2005) Perfil de competências empreendedoras dos investidores portugueses e brasileiros: um estudo comparativo na rede hoteleira do Ceará. In: In: Encontro Nacional Da Associação Nacional De Pósgraduação E Pesquisa Em Administração, 29, 2005, Brasília. Anais.Rio de Janeiro: Anpad.

Mattar, F. (1996) Pesquisa de marketing. São Paulo: Atlas.

Maximiano, A. C. A. (1995) Introdução à administração. 4. ed. São Paulo: Atlas.

Mcclelland, D. C. (1972) A sociedade competitiva: realização e progresso social. Rio de Janeiro: Expressão e Cultura.

Moore, D. P., \& Buttner, E. H. (1997) Women entrepreneurs. London: Sage Publications.

Murray, H. J. (1973) Motivação e emoção. Rio de Janeiro: Zahar.

Pereira, A. B. et al. (2013) Análise do perfil, características e tipos de empreendedores: estudo de caso na cidade de Curitiba-pr. Disponível em: <http://www.santacruz.br/v4/download/revista-academica/17/08-analise-do-perfil caracteristicas-e-tipos-de-empreendedores.pdf $>$. Acesso em: 14 jan. 2018.

Puente, M. (1982) Tendências Contemporâneas em Psicologia da Motivação. São Paulo: Cortes.

Rampazzo, L. (2005) Metodologia cientifica: para alunos de dos cursos de graduação e pós graduação. 3 ed. São Paulo: Edições Loyola.

Santos, S. C., Caetano, A., \& Curral, L. (2010) Atitude dos estudantes universitários face ao empreendedorismo: Como identificar o potencial empreendedor?. Disponível em: $<$ http://repositorio.ul.pt/bitstream/10451/11007/1/Correia Santos, Caetano e 
Curral_2010_RPBG por.pdf>. Acesso em: 25 fev. 2018.

Schumpeter, J. A. (1997) Teoria do desenvolvimento econômico. Uma investigação sobre lucros, capital, crédito, juro e o ciclo econômico. São Paulo: Nova Cultural.

SEBRAE. (2017) Educação empreendedora: Tendências em educação empreendedora: aprendizado para quem sonha alto. Disponível em: $<$ http://www.sebrae.com.br/sites/PortalSebrae/artigos/tendencias-em-educacao empreendedora-aprendizado-para-quem-sonhaalto,9fb982fdc7c8b510VgnVCM1000004c00210aRCRD>. Acesso em: 29 maio 2018.

Siegel, S., \& Castellan, Jr, N.J. (2006) Estatística Não Paramétrica para as Ciências do Comportamento. São Paulo: Artmed-Bookman.

Silva, L. R.; \& Chiusoli, C. L. (2016) Empreendedorismo: o que pensam os estudantes do curso de administração da unicentro na visão empreendedor In: VI Congresso de Ciências Sociais Aplicadas - CONCISA - Estratégia e Inovação, Guarapuava/Pr.

Veras, G. (1999) Como ser empresário. Revista Jovem Empreendedor. Florianópolis: Editora Empreendedor. 